\title{
Comparison of Causes of Loneliness and Coping Behaviors Among Japanese and Chinese University Student Samples
}

\author{
YING XIE*1), YUJIRO KAWATA*1) 2), AKARI KAMIMURA*2) 3), NOBUTO SHIBATA*1) 2) \\ *1) Graduate School of Health and Sports Science, Juntendo University, Chiba, Japan, ${ }^{* 2)}$ Faculty of Health and Sports \\ Science, Juntendo University, Chiba, Japan, *3) School of Humanities, Wayo Women’s University, Chiba, Japan
}

Objective: This study aimed to: (a) develop scales for measuring the causes of and coping behaviors with loneliness in Japanese and Chinese university students and (b) compare the interrelationships between the causes of loneliness, sense of loneliness, and coping behaviors with loneliness among Japanese and Chinese student samples.

Participants: In the preliminary survey, participants were 111 Japanese $(\mathrm{M}=20.06, \mathrm{SD}=1.34)$ and 83 Chinese university students $(\mathrm{M}=18.90, \mathrm{SD}=1.20)$. In the main survey, 864 Japanese $(\mathrm{M}=18.95, \mathrm{SD}=0.967)$ and 414 Chinese university students $(\mathrm{M}=19.94, \mathrm{SD}=1.27)$ participated.

Methods: In the preliminary survey, items from the Loneliness Cause Scale and Coping Behaviors with Loneliness Scale were extracted during the open-ended interviews with Japanese and Chinese university students. The main survey was conducted with Japanese and Chinese university students, using a questionnaire which included three parts: UCLA Loneliness Scale, Loneliness Cause Scale, and Coping Behaviors with Loneliness Scale.

Results and Conclusion: The researchers developed a Loneliness Cause Scale and Coping behaviors with Loneliness Scale. The causes of loneliness consisted of 3 factors, while coping behaviors included 4 factors. Chinese university students felt a strong sense of loneliness and were more aware of the cause of their loneliness compared to Japanese university student samples. Regarding coping behaviors with loneliness, Japanese university students tended to choose "interpersonal contacts" and "diversions and pastimes," while their Chinese counterparts engaged in the "use of social media."

Key words: loneliness, coping behaviors, Japan, China, university students

\section{Introduction}

On January 18, 2018, a minister for Loneliness was appointed in Great Britain. The story was covered by international media ${ }^{1)}$ because it was unprecedented for a government to intervene in the field concerning a person's inner mind such as "loneliness." In recent years, loneliness has become a theme that is increasingly attracting worldwide attention.

\section{What is loneliness?}

Numerous social scientists disagree with their definition of loneliness because of differences in theoretical backgrounds. ${ }^{2)}$ For example, Sullivan ${ }^{3)}$ defines loneliness as, "the exceedingly unpleasant and driving experience connected with inadequate discharge of the need for human intimacy, for interpersonal intimacy." Perlman and Peplau ${ }^{4)}$ defines loneliness as "an unpleasant experience that occurs when a person's network of social relations is deficient in some important way, either quantitatively or qualitatively." Peplau and Perlman ${ }^{5)}$ cited three characteristics common to the diverse definition of loneliness: (1) It results from a deficiency in a person's social relationship, (2) is a

Corresponding author: Yujiro Kawata

Graduate School of Health and Sports Science, Juntendo University

1-1 Hirakagakuendai, Inzai-shi, Chiba 270-1606, Japan

TEL: + 81-476-98-1001 FAX: +81-476-98-1001 E-mail: yuukawa@juntendo.ac.jp

〔Received Aug. 12, 2020] (Accepted Oct. 12, 2020〕

J-STAGE Advance published date: Dec. 11, 2020

Copyright (C) 2021 The Juntendo Medical Society. This is an open access article distributed under the terms of Creative Commons Attribution License (CC BY), which permits unrestricted use, distribution, and reproduction in any medium, provided the original source is properly credited. doi: 10.14789/jmj.2021.67.JMJ20-OA08 
subjective experience and differentiated from objective social isolation, and (3) is an unpleasant and aversive experience.

According to the Jo Cox Commission, ${ }^{6)}$ loneliness has an impact on people of all age groups and social backgrounds. Furthermore, it is reported to be accompanied by a range of physical and mental signs and symptoms, including reduced selfesteem, depression, and anxiety. ${ }^{7)}{ }^{8)}$

Studies in developmental psychology revealed that individuals perceive loneliness frequently and intensely, especially during adolescence. ${ }^{3)}{ }^{9)}$ In a survey conducted by the BBC that targeted 55,000 people of different age groups worldwide, $40 \%$ of young people aged 16-24 reported that they "frequently felt lonely," showing that a large number of individuals in this age group suffered with loneliness. ${ }^{10)}$ Loneliness experienced among adolescents occurs at a time in their lives when they separate from the parent-child relationship, which used to be close and friendly, and are forced to build new, close, and friendly relationships with other people. However, if they fail to build new relationships, they begin to feel that understanding and empathy between people is hard to achieve, and they are alone. ${ }^{11)}$

\section{Loneliness among young people in Japan and China}

A survey conducted in 21 countries by the Organization for Economic Co-operation and Development (OECD) found that Japan had the largest percentage of men reported that they "do not have much time to spend with friends and/or coworkers." Japanese women ranked second, following top-ranked Mexico. ${ }^{12)}$ In 2007, a survey conducted by the United Nations Children's Fund (UNICEF) on the well-being of children in 24 highly developed countries revealed that Japan ranked first in terms of the percentage $(29.8 \%)$ of 15-year-olds who felt they were lonely, followed by Iceland in second place (10.3\%) and Poland in third (8.4\%). ${ }^{13)}$ These results suggest that Japanese people are more prone to experiencing loneliness than people in other countries.

A study was conducted on the lives of Japanese university students many years ago. The researchers looked at terms such as "bocchi-seki" or "seats for single people" (sitting alone in class, away from others) and "benjo-meshi" or "eating inside the toilet" (eating food in the bathroom so others do not see them eating alone). The study described how students could not tolerate others seeing them as being solitary or lonely without friends. A report entitled, "Young people who cannot stand loneliness" was published by Haryu and Seto in 2011. ${ }^{14)}$ The popularity and widespread use of social media made it easy to connect to numerous people. However, it is now a phenomenon that is making many young people feel lonely, indicating that loneliness in adolescence is changing.

The current state of loneliness in young people in Japan and China is serious. A survey by Luo et al. ${ }^{15)}$ showed that $83.9 \%$ of university students felt lonely, either "all the time" or "occasionally." To clarify these situations in detail, an international comparative study ${ }^{16)}$ mentioned that there is a need to identify cultural similarities and differences of loneliness in Chinese university students.

China and Japan belong to the same oriental zone, with a long history of trading and numerous similarities in terms of culture, lifestyle, and language. ${ }^{17)}$ Moreover, Wang and Imagawa ${ }^{18)}$ noted that along with the rapid growth of China's economy, the growth of mass media and advancements in the IT revolution are changing the environment of young Chinese people, and influencing their interpersonal relationships, especially with their peers similar to those of developed countries. Loneliness is more likely to develop during adolescence because of peer relationships; ${ }^{11)}$ therefore, loneliness perceived by young people in China and Japan may share commonalities. Japan and China operate under different social conditions and circumstances, ${ }^{17)}$ and a few studies investigate the similarities and differences between loneliness among adolescents living in environments with distinct characteristics.

Peplau and Perlman ${ }^{5)}$ pointed out that to understand loneliness in detail, it is necessary to distinguish the preconditions or causes from the actions and behaviors used to cope with it. However, there were problems in understanding these characteristics in Japan and China. Currently, the University of California, Los Angeles Loneliness Scale (UCLA LS) developed by Russell ${ }^{19)}$ is a method used to measure loneliness in adolescence worldwide. $^{20)}$ The scale has been modified to 
Version 3, and both Japanese and Chinese language editions have been formulated. ${ }^{21)}$ 22) Although scales are available for both Japanese and Chinese subjects to measure the causes and coping behaviors with loneliness, ${ }^{23)-26)}$ there are no scales for measuring the preconditions (causes) of loneliness or the methods to cope with it (the resultant coping behaviors) in Japan and China. Therefore, there is a need to develop a scale that is equally applicable to Japanese and Chinese students and to compare the characteristics of loneliness. This type of scale will be useful for understanding the characteristics of loneliness among Japanese and Chinese university students, and for proposing psychological assistance to students who suffer with intense loneliness.

This study aimed to (a) develop scales for measuring the causes of loneliness and coping behaviors with loneliness, which can be used in Japan and China; and (b) compare the interrelationships between the causes of loneliness, a sense of loneliness, and coping behaviors for such loneliness among Japanese and Chinese university student samples.

\section{Preliminary survey}

\section{Purpose and methods}

To select the items for these scales that measured the causes and coping behaviors of loneliness, we conducted the survey with a free descriptive-type questionnaire survey between November 2015 and May 2016. The subjects were 194 students from 3 universities in Japan and China (Japan: 67 males and 44 females, average age $=20.06$ years, $\mathrm{SD}=$ 1.34; China: 34 males and 49 females, average age $=18.90$ years, $\mathrm{SD}=1.20$ ).

In Japan, the survey was conducted in a classroom. The questionnaires were handed out and collected. In China, the survey was sent by post to teachers at various universities, and was conducted using the same method as in Japan.

The study was conducted after obtaining the approval of Juntendo University Graduate School of Health and Sports Sciences ethics committee (Graduate School 29-98). The introduction of the questionnaire clearly explained that answering the questions was not compulsory or enforced, the survey was done anonymously, the findings would be used for research purposes only, and the data would be statistically analyzed, which could not identify the results of any particular individual.

The questionnaire followed the method used by Hirosawa ${ }^{24)}$, who conducted studies on loneliness. It was composed of (1) the subjects' attributes (nationality, sex, age, and affiliated university and department), (2) current status of loneliness (whether loneliness is experienced or not), (3) a free descriptive-type question on the causes of loneliness ("What do you think can trigger loneliness in you?"), and (4) an open-ended question on actions and behaviors used to cope with loneliness ("What actions and behaviors do you typically engage in when you feel lonely?"). All questions and options were translated into Chinese by the lead author and two Chinese exchange students fluent in Japanese. The questions were back-translated by the university faculty member who lived in Japan for many years and whose native language is Chinese, which assured homogeneity of the content.

Analytical procedures were carried out using the Kawakita Jiro (KJ) method ${ }^{27)}$ and classified by five individuals: the lead author, a graduate student majoring in psychology, two university faculty members specializing in psychology, and a psychiatrist.

\section{Results and discussion}

In total, 70 Japanese students (63.0\%) and 70 Chinese students (84.3\%) reported that they perceived loneliness. 162 items (86 items for Japan and 76 for China) were obtained from extracting the meaning unit (content that matches the concept about to be extracted) that was the cause of loneliness. 252 items (125 for Japan and 127 for China) were obtained from extracting the meaning unit in coping behaviors with loneliness. The KJ method was used to classify similar units, indicating 23 items as the cause of loneliness (Table-1) and 37 items as coping behaviors (Table-2). The findings were used for subsequent research.

Many items concerning the cause of loneliness (Table-1) were the same for the Japanese and Chinese university students. However, Japanese university students tended to feel lonely because of interpersonal anxieties such as feeling out of place, failing to blend in with the people around them, or being rejected by others. Chinese university students, also reported perceiving loneliness when their opinions did not match those of their parents, 
Table-1 Classification table of the cause of loneliness

\begin{tabular}{|c|c|c|c|}
\hline No. & Items & JPN & $\mathrm{CHN}$ \\
\hline 1 & Because my opinions did not match of my parents & & O \\
\hline 2 & Because no one understands me & $\bigcirc$ & $\bigcirc$ \\
\hline 3 & When I want to talk, I can't find the listener & $\bigcirc$ & $\bigcirc$ \\
\hline 4 & Because there is no one to rely on & $\bigcirc$ & $\bigcirc$ \\
\hline 5 & Because I have no friends I knew and could trust & & $\bigcirc$ \\
\hline 6 & Because I don't have a lover & $\bigcirc$ & $\bigcirc$ \\
\hline 7 & Because I have no people whom I could share hobbies with & & $\bigcirc$ \\
\hline 8 & Because the lack of direct communication with others due to the development of SNS & $\bigcirc$ & $\bigcirc$ \\
\hline 9 & Because I feel like failing to blend in others & $\bigcirc$ & \\
\hline 10 & Because I feel like being rejected by others & $\bigcirc$ & \\
\hline 11 & $\begin{array}{l}\text { Because physical symptoms occur due to stress or hormonal balance } \\
\text { (such as menstruation) }\end{array}$ & $\bigcirc$ & $\bigcirc$ \\
\hline 12 & Because I can't feel the caring heart around me & $\bigcirc$ & \\
\hline 13 & Because I am not confident & $\bigcirc$ & $\bigcirc$ \\
\hline 14 & Because experienced failure or frustration in study or work & $\bigcirc$ & $\bigcirc$ \\
\hline 15 & Because I have an ordinary life & & $\bigcirc$ \\
\hline 16 & Because I have been alone for a long time & $\bigcirc$ & $\bigcirc$ \\
\hline 17 & Because I live alone & $\bigcirc$ & \\
\hline 18 & Because I am not good at revealing my feelings & & $\bigcirc$ \\
\hline 19 & Because I am used to being with others & $\bigcirc$ & O \\
\hline 20 & Because I think too pessimistically & $\bigcirc$ & \\
\hline 21 & Because I do not actively communicate with people & $\bigcirc$ & \\
\hline 22 & Because I am separated from people close to me & $\bigcirc$ & \\
\hline 23 & Because the environment has changed due to going on to school, getting a job, moving, etc. & $\bigcirc$ & \\
\hline
\end{tabular}

Note: $\bigcirc$ The items appear in the answer, JPN= Japanese, $\mathrm{CHN}=$ Chinese

when they had no trustworthy friends or people with who they could share their hobbies, and for other reasons.

Many items concerning behaviors for coping with loneliness (Table-2) were the same for the Japanese and Chinese university students. The Japanese students endured or had a neutral attitude, as described in phrases such as "enjoy being alone" and "try not to care too much." The Chinese students expressed themselves in writing, engaged in sports, and took pictures to cope with loneliness.

\section{The main survey}

\section{Methods}

1) Survey period and subjects

The Chinese survey was conducted from November to December 2017, targeting 446 university students from 1 university in Beijing, China and the South-Central district of China; and 3 in the South
China region. In total, 414 subjects gave valid responses (166 male students, 248 female students; mean age $=19.94$ years; $\mathrm{SD}=1.27$ ).

The Japanese survey was conducted from April to May 2018, targeting 914 university students enrolled in 3 Japanese universities in the Tokyo metropolitan area and 1 university in the Chûgoku area. In total, 864 subjects gave valid responses (421 male students, 443 female students; mean age $=18.95$ years; $\mathrm{SD}=0.97$ )

The objectives of the Japanese study were explained in advance to the university teachers, who agreed to assist by using time after class to conduct the survey. Questionnaires were given directly to the students, after answering the questions, it was collected promptly. The Chinese, survey was sent by post to the university teachers who agreed to assist, using the same method as Japan.

This study was implemented after obtaining the 
Table-2 Category classification table for coping with loneliness

\begin{tabular}{|c|c|c|c|}
\hline No. & Items & JPN & $\mathrm{CHN}$ \\
\hline 1 & Always endure & $\bigcirc$ & $\bigcirc$ \\
\hline 2 & Wait for time to pass & $\bigcirc$ & $\bigcirc$ \\
\hline 3 & Enjoy being alone & $\bigcirc$ & \\
\hline 4 & Do nothing & $\bigcirc$ & $\bigcirc$ \\
\hline 5 & Lost in thought & $\bigcirc$ & \\
\hline 6 & Try not to care too much & $\bigcirc$ & \\
\hline 7 & Sleep & $\bigcirc$ & $\bigcirc$ \\
\hline 8 & Go play with someone & $\bigcirc$ & $\bigcirc$ \\
\hline 9 & Meet someone & $\bigcirc$ & $\bigcirc$ \\
\hline 10 & Pampered by my parents & $\bigcirc$ & $\bigcirc$ \\
\hline 11 & Call someone & $\bigcirc$ & $\bigcirc$ \\
\hline 12 & Contact someone via social media & $\bigcirc$ & $\bigcirc$ \\
\hline 13 & Posting information on social media & $\bigcirc$ & $\bigcirc$ \\
\hline 14 & Browsing information on social media & & $\bigcirc$ \\
\hline 15 & Go to movies and plays & $\bigcirc$ & $\bigcirc$ \\
\hline 16 & Watch TV & $\bigcirc$ & \\
\hline 17 & Watch videos online & O & $\bigcirc$ \\
\hline 18 & To read & $\bigcirc$ & $\bigcirc$ \\
\hline 19 & Play a game & $\bigcirc$ & $\bigcirc$ \\
\hline 20 & Play with my mobile phone & $\bigcirc$ & $\bigcirc$ \\
\hline 21 & Enthusiastic about something & $\bigcirc$ & $\bigcirc$ \\
\hline 22 & Sing a song & $\bigcirc$ & $\bigcirc$ \\
\hline 23 & Smoking cigarettes & $\bigcirc$ & $\bigcirc$ \\
\hline 24 & Go out & $\bigcirc$ & \\
\hline 25 & Rethink myself & & $\bigcirc$ \\
\hline 26 & Think positive & & $\bigcirc$ \\
\hline 27 & Cut loose & & $\bigcirc$ \\
\hline 28 & Taking it out on others for no reason & & $\bigcirc$ \\
\hline 29 & Be alone & $\bigcirc$ & $\bigcirc$ \\
\hline 30 & I throw myself into work or study & $\bigcirc$ & $\bigcirc$ \\
\hline 31 & Posting texts on the Internet & & $\bigcirc$ \\
\hline 32 & Expressing oneself in writing & & $\bigcirc$ \\
\hline 33 & Play sports & & $\bigcirc$ \\
\hline 34 & Take a picture & & $\bigcirc$ \\
\hline 35 & Eat something & $\bigcirc$ & $\bigcirc$ \\
\hline 36 & To shop & & 0 \\
\hline 37 & Crying & 0 & 0 \\
\hline
\end{tabular}

Note: $\bigcirc$ The items appear in the answer, JPN = Japanese, $\mathrm{CHN}=$ Chinese

approval of Juntendo University Graduate School of Health and Sports Sciences' Ethics Committee (Graduate School 29-98). The introduction of the questionnaire used in the survey explained that answering the questions was optional and the subjects could refuse to participate, the survey was done anonymously, the findings would be used for research purposes only, and the data would be statistically analyzed, which could not identify the results of any particular individual.

2) Composition of the questionnaire

\section{(1) Subjects' attributes}

Subjects were asked about their nationality, sex, age, affiliated department, current lifestyle, and siblings (yes/no).

(2) Scale items for measuring the causes of loneliness

Items on the scales for measuring the causes of loneliness were developed based on the 23 items extracted in the preliminary survey, upon agreement by the lead author, two university teachers specializing in psychology, and a psychiatrist. The following instruction was provided: "Read the following items on what causes feelings of loneliness and circle the option that applies to you the most." The subjects were asked to answer each item on a four-point Likert scale ranging from "Strongly disagree (1 point)" to "Strongly agree (4 points)."

(3) Scale items for measuring coping behaviors with loneliness

Items on the scales for measuring coping behaviors with loneliness were developed based on the 37 items extracted in the preliminary survey, upon agreement by the lead author, two university teachers specializing in psychology, and a psychiatrist. The following instruction was provided: "Read the following items regarding the extent of behaviors you normally engage in, when you feel lonely and circle the option that applies to you the most." Subjects were asked to answer each item on a four-point Likert scale ranging from "Never (1 point)" to "All the time (4 points)."

(4) UCLA Loneliness Scale, Version 3

To evaluate the loneliness of university students in China and Japan, we used the UCLA Loneliness Scale Version 3 developed by Russell. ${ }^{212}{ }^{22}{ }^{28)}$ The UCLA scale is composed of 20 items and 1 factor structure. The subjects were asked to answer the extent to which they normally perceived the content of each item on a four-point Likert scale ranging from "Never (1 point)" to "All the time (4 points)."

Method of analysis: Statistical software SPSS 
ver.21 and Amos ver.21 were used to analyze the results.

\section{3) Analysis I}

Process of analysis: Item analyses were performed. Internal consistency (Cronbach's alpha) was confirmed to verify the reliability of the scale. Validity was determined using content validity (examination of the floor and ceiling effect), construct validity (exploratory factor analysis), and criterion-related validity (correlation analysis).

For criterion-related validity, correlation analysis was performed between the Loneliness Cause Scale and UCLA Loneliness Scale. The former scale revealed that the higher the score, the greater a person's degree of loneliness or social isolation. Therefore, in this study, a positive correlation indicated validity. Correlation analysis was performed between the Loneliness Coping Behavior Scale and UCLA Loneliness Scale. The focus on behavior and action can have two effects; it can be effective as a coping behavior and can have negative effects. Therefore, showing both positive and negative correlations indicated validity.

\section{4) Results and discussion}

\section{(1) The Loneliness Cause Scale}

The results of the item analysis showed the floor effect for "because I am living on my own" ( $\mathrm{M}=$ 1.76, $\mathrm{SD}=0.85)$. This item was deleted after examining its content and standard deviation, therefore, the analysis was performed on 22 items.

An exploratory factor analysis (maximum likelihood method; promax rotation) was implemented to identify the factors that cause loneliness. The results showed that three factors were reasonable, in view of the attenuation status of eigenvalues $(8.86,1.45,1.20,1.10 \ldots . .$.$) and possibilities for$ interpretation of the factors. The precision of the scales was enhanced by eliminating items with loadings less than 0.40 and by performing a factor analysis again, using the remaining 12 items. The results indicated that three factors with each item confirmed to have adequate factor loading $(0.40$ or more). Therefore, the Loneliness Cause Scale, adopted 3 factors and 12 items, and based on the content of the items, each factor was named as follows: Factor 1: "Absence of supporters and sympathizers," Factor 2: "Introverted thoughts," and Factor 3: "Changes in the environment" (Table-3).

To investigate reliability (internal consistency), Cronbach's alpha $(\alpha)$ was calculated. The results showed $\alpha$ to be 0.89 for "absence of supporters and sympathizers," 0.82 for "introverted thoughts," and 0.71 for "changes in the environment," which at 0.70 or greater, were enough values. Therefore, the total scores of each factor was the scores obtained for "absence of supporters and sympathizers," "introverted personality," and "changes in the environment," respectively.

To investigate criterion-related validity, Pearson's product-moment correlation coefficient was calculated between the scores for the UCLA Loneliness Scale and factor scores for the Loneliness Cause Scale. The results showed a high positive correlation between "absence of supporters and sympathizers" $(r=0.78, p<0.001)$ and "introverted thoughts" $(r=0.73, p<0.001)$, while confirming enough values for a moderately positive correlation with "changes in the environment" $(\mathrm{r}=$ $0.53, \mathrm{p}<0.001$ ).

An overview of preceding studies shows that the Loneliness Cause Scale developed for Japanese university students outlined the following five factors: "Lack of active interpersonal contacts," "interpersonal alienation," "lack of opportunities and changes in the environment," "social phobia," and "personality and differences in ways of thinking." ${ }^{29)}$, A study conducted on the cause of loneliness in Chinese university students attempted to interpret the causes of loneliness using subjective elements such as "personality," "lack of social skills," and "evaluation of the self and by others," and external social environmental elements such as "school life," "parents' childrearing attitudes," and "internet addiction." 30)

The causes of loneliness were based on the subjective and external social environmental elements. The five-factor causes of loneliness identified in Japan's preceding study considered "lack of active interpersonal contacts," "interpersonal alienation," "social phobia," and "personality and differences in ways of thinking", as the subjective elements, and "lack of opportunities" and "changes in the environment" as the external social environmental elements. The three factors in this study considered "absence of supporters and 
Table-3 Factorial analysis of The Loneliness Cause Scale

\begin{tabular}{|c|c|c|c|c|c|c|c|}
\hline No. & Items & M & $\mathrm{SD}$ & F1 & $\mathrm{F} 2$ & F3 & $h^{2}$ \\
\hline \multicolumn{8}{|c|}{$<\mathrm{F} 1$ Absence of supporters and sympathizers: $\mathrm{M}=2.20, \mathrm{SD}=.77, \alpha=.89>$} \\
\hline 4. & Because there is no one to rely on & 2.19 & .91 & .91 & -.04 & .00 & .78 \\
\hline 5. & Because I have no friends I knew and could trust & 2.19 & .88 & .81 & .10 & -.10 & .67 \\
\hline & Because no one understands me & 2.18 & .87 & .76 & -.02 & .07 & .64 \\
\hline 3. & When I want to talk, I can't find the listener & 2.27 & .87 & .76 & .00 & .04 & .61 \\
\hline \multicolumn{8}{|c|}{$<\mathrm{F} 2$ Introverted thoughts: $\mathrm{M}=2.31, \mathrm{SD}=.73, \alpha=.82>$} \\
\hline & Because I am not good at revealing my feelings & 2.31 & .93 & .00 & .77 & -.05 & .54 \\
\hline & Because I am not confident & 2.49 & .92 & .02 & .70 & .00 & .50 \\
\hline & Because I think too pessimistically & 2.19 & .92 & -.06 & .68 & .15 & .57 \\
\hline & Because I do not actively communicate with people & 2.25 & .89 & .11 & .66 & -.02 & .53 \\
\hline \multicolumn{8}{|c|}{$<\mathrm{F} 3$ Changes in the environment: $\mathrm{M}=2.10, \mathrm{SD}=.64, \alpha=.71>$} \\
\hline & $\begin{array}{l}\text { Because the environment has changed due to going on to school, getting a job, } \\
\text { moving }\end{array}$ & 2.13 & .91 & -.05 & .00 & .73 & .49 \\
\hline & Because I am separated from people close to me & 1.89 & .84 & .11 & -.04 & .64 & .46 \\
\hline & Because I am used to being with others & 2.17 & .87 & -.04 & .02 & .53 & .28 \\
\hline \multirow[t]{7}{*}{14.} & Because experienced failure or frustration in study or work & 2.23 & .88 & .08 & .20 & .40 & .38 \\
\hline & Eigen value & & & 4.96 & .97 & .51 & \\
\hline & $\%$ contribution ratio & & & 41.37 & 8.09 & 4.24 & \\
\hline & \%cumulative contribution ratio & & & 41.37 & 49.46 & 53.70 & \\
\hline & Inter-factor correlations & & & $\mathrm{F} 1$ & $\mathrm{~F} 2$ & F3 & \\
\hline & & & $\mathrm{F} 2$ & .64 & & & \\
\hline & & & F3 & .58 & .68 & & \\
\hline
\end{tabular}

Note: maximum likelihood method, Promax rotation

sympathizers" and "introverted thoughts" as subjective elements, and "changes in the environment" as the external social environmental element.

\section{(2) Scale for Coping behaviors with Loneliness}

The item analysis revealed floor effects for the following five items: "Smoking cigarettes $(\mathrm{M}=$ $1.26, \mathrm{SD}=0.77$ ), "Taking it out on others for no reason" $(\mathrm{M}=1.84, \mathrm{SD}=0.96)$, "Posting texts on the Internet" $(\mathrm{M}=1.71, \mathrm{SD}=0.92)$, "Expressing oneself in writing” $(\mathrm{M}=1.77, \mathrm{SD}=0.99)$, and “Crying” $(\mathrm{M}=2.07, \mathrm{SD}=1.18)$. The 5 items were deleted after examining the content and standard deviation, and performed a factor analysis (maximum likelihood method; promax rotation) using 32 items.

Factor analysis was performed to identify the factors of coping behaviors with loneliness (maximum likelihood method; promax rotation), therefore, in view of the attenuation status of eigenvalues $(5.77,3.30,2.41,1.85,1.59,1.17 \ldots . .$.$) and possibil-$ ities for interpretation of the factors, the results found the four factors reasonable. To enhance the precision of the scales, items with loadings less than
0.40 were eliminated, and the factor analysis was repeated by using the remaining ten items. Results indicated that the four factors were the same with each item confirmed to have enough factor loadings. We therefore decided to adopt ten items for the Scale for Coping behaviors with Loneliness. We named each factor as follows: Factor 1: "Interpersonal contacts," Factor 2: "Diversions and pastimes," Factor 3: "Enduring and standing," and Factor 4, "Use of social media" (Table-4).

Internal consistency was determined by calculating Cronbach's alpha. The results indicated $\alpha$ (alpha) as 0.89 for "interpersonal contacts," 0.69 for "diversions and pastimes," 0.83 for "enduring and standing by," and 0.71 for "use of social media," which was considered similar, although the alpha coefficient for "diversions and pastimes" was somewhat low. The total scores of each factor were the scores obtained from interpersonal contacts, diversions and pastimes, enduring and standing by, and use of social media, respectively.

Criterion-related validity was determined by 
Table-4 Factorial analysis of Scale for Coping Behaviors with Loneliness

\begin{tabular}{|c|c|c|c|c|c|c|c|c|}
\hline No. & Items & M & $\mathrm{SD}$ & F1 & F2 & F3 & $\mathrm{F} 4$ & $\mathrm{~h}^{2}$ \\
\hline \multicolumn{9}{|c|}{$<$ F1 Interpersonal contacts: $\mathrm{M}=3.30, \mathrm{SD}=1.05, \alpha=.89>$} \\
\hline 8. & Go play with someone & 3.33 & 1.09 & .90 & .01 & .01 & .02 & .79 \\
\hline 9. & Meet someone & 3.26 & 1.12 & .88 & .02 & -.01 & -.01 & .83 \\
\hline \multicolumn{9}{|c|}{$<$ F2 Diversions and pastimes: $\mathrm{M}=3.65, \mathrm{SD}=.87, \alpha=.69>$} \\
\hline 17. & Watch videos online & 3.66 & 1.12 & -.05 & .85 & -.05 & -.08 & .64 \\
\hline & Play with my mobile phone & 4.01 & .98 & -.02 & .62 & .06 & .16 & .50 \\
\hline 16. & Watch TV & 3.28 & 1.21 & .15 & .53 & -.02 & -.01 & .31 \\
\hline \multicolumn{9}{|c|}{$<$ F3 Enduring and standing: $\mathrm{M}=3.17, \mathrm{SD}=.99, \alpha=.83>$} \\
\hline 2. & Wait for time to pass & 3.26 & 1.06 & .07 & .02 & .96 & -.06 & .92 \\
\hline 1. & Always endure & 3.08 & 1.09 & -.08 & -.04 & .74 & .05 & .57 \\
\hline \multicolumn{9}{|c|}{$<$ F4 Use of social media: $\mathrm{M}=2.90, \mathrm{SD}=.96, \alpha=.71>$} \\
\hline 13. & Posting information on social media & 2.37 & 1.14 & -.04 & -.16 & -.01 & .76 & .49 \\
\hline & Browsing information on social media & 3.22 & 1.25 & -.09 & .21 & .03 & .64 & .53 \\
\hline \multirow[t]{8}{*}{12.} & Contact someone via social media & 3.10 & 1.25 & .20 & -.01 & -.03 & .60 & .47 \\
\hline & Eigen value & & & 1.69 & 2.23 & 1.31 & .81 & \\
\hline & \%contribution ratio & & & 16.93 & 22.34 & 13.09 & 8.12 & \\
\hline & \%cumulative contribution ratio & & & 16.93 & 39.27 & 52.35 & 60.47 & \\
\hline & Inter-factor correlations & & & $\mathrm{F} 1$ & $\mathrm{~F} 2$ & F3 & F4 & \\
\hline & & & $\mathrm{F} 2$ & .29 & & & & \\
\hline & & & F3 & -.18 & .18 & & & \\
\hline & & & $\mathrm{F} 4$ & .29 & .42 & .01 & & \\
\hline
\end{tabular}

Note: maximum likelihood method, Promax rotation

calculating Pearson's product-moment correlation coefficient between the scores for the UCLA Loneliness Scale and the factor scores on the Scale for Coping behaviors with Loneliness. The results demonstrated a low negative correlation with "interpersonal contacts" $(\mathrm{r}=-0.35, \mathrm{p}<0.001)$ and a low positive correlation with "enduring and standing by" $(r=0.28, p<0.001)$. There was no significant correlation evident in "diversions and pastimes" and "use of social media." Thus, criterion-related validity was not confirmed for "diversions and pastimes" or "use of social media." However, the results of the preliminary and main surveys showed that these behaviors exist, therefore, it was used in subsequent analyses. The results also showed that the sense of loneliness and isolation individual subjects experienced were not necessarily behaviors induced to cope with these aspects, e.g., "diversions and pastimes" and "use of social media."

An overview of the preceding studies revealed various views regarding the structure (factors) of coping behaviors. ${ }^{25)}{ }^{29)}{ }^{31}{ }^{32)}$ The Scale for Coping behaviors with Loneliness, developed for Japanese university students, uses the following seven factors: "Diversions and distractions," "immersion in hobbies and work," "interpersonal contacts," "enduring and standing by," "resorting to familiar actions and behaviors," "emotionality and escape," and "amae (acting like a spoiled child)." ${ }^{29)}$ In China, the researchers ${ }^{33)}$ followed the views of Rubenstein ${ }^{31)}$ and perceived coping behaviors with loneliness from three perspectives: "Brooding: passive-evasive reactions," "emotional expressions and social responses," and "constructive and active responses." However, all coping behaviors attempt to commit to social relationships, are non-resistive (enduring) and have passive behaviors to fight loneliness or seek compensations such as engaging with and immersing oneself in non-interpersonal activities $^{25)}$. In this study also, "interpersonal contacts" and "use of social media" coincide with activities that attempt to commit to social relationships: "Enduring and standing by," with nonresistant (enduring) and have passive behaviors to fight loneliness; and "diversions and pastimes," 
Table-5 Subjects' basic attributes

\begin{tabular}{|c|c|c|c|c|c|}
\hline & & JPN & $\%$ & $\mathrm{CHN}$ & $\%$ \\
\hline \multirow[t]{2}{*}{ Gender } & Male & 421 & 48.73 & 166 & 40.10 \\
\hline & Female & 443 & 51.27 & 248 & 59.90 \\
\hline \multirow[t]{4}{*}{ Age } & $17 \sim 18$ & 348 & 40.28 & 51 & 12.32 \\
\hline & $19 \sim 20$ & 476 & 55.09 & 257 & 62.08 \\
\hline & $21 \sim 22$ & 38 & 4.40 & 93 & 22.46 \\
\hline & $23 \sim 25$ & 2 & .23 & 13 & 3.14 \\
\hline \multirow[t]{6}{*}{ Grade } & Freshman & 457 & 52.89 & 125 & 30.19 \\
\hline & Sophomore & 205 & 23.73 & 131 & 31.64 \\
\hline & Junior & 194 & 22.45 & 126 & 30.43 \\
\hline & Senior & 7 & .81 & 30 & 7.25 \\
\hline & Fifth grade (Medicine) & - & - & 2 & .48 \\
\hline & Sixth grade (Medicine) & 1 & .12 & - & - \\
\hline \multirow[t]{3}{*}{ Department } & Humanities & 709 & 82.06 & 151 & 36.47 \\
\hline & Social science & 91 & 10.53 & 102 & 24.64 \\
\hline & Natural science (Medicine) & 64 & 7.41 & 161 & 38.89 \\
\hline \multirow[t]{7}{*}{ Present Living form } & Living alone & 225 & 26.04 & 2 & .48 \\
\hline & Parents' House & 245 & 28.36 & 20 & 4.83 \\
\hline & Live with friends & 20 & 2.31 & 10 & 2.42 \\
\hline & Dormitory & 361 & 41.78 & 380 & 91.79 \\
\hline & Live with a lover & 2 & .23 & 1 & .24 \\
\hline & Live with relatives & 5 & .58 & 1 & .24 \\
\hline & Others & 6 & .69 & - & - \\
\hline \multirow[t]{2}{*}{ Brothers and sisters } & Yes & 777 & 89.93 & 200 & 48.31 \\
\hline & No & 87 & 10.07 & 214 & 51.69 \\
\hline \multirow[t]{2}{*}{ Friends } & Yes & 813 & 94.10 & 405 & 97.83 \\
\hline & No & 51 & 5.90 & 9 & 2.17 \\
\hline \multirow[t]{2}{*}{ Lover } & Yes & 217 & 25.12 & 122 & 29.47 \\
\hline & No & 647 & 74.88 & 292 & 70.53 \\
\hline
\end{tabular}

Note: 3 less than 17-yers-old Chinese participants were included because of their skipping grade. JPN= Japanese, $\mathrm{CHN}=$ Chinese

with behaviors that seek compensations such as engaging with and immersing oneself in non-interpersonal activities.

\section{5) Analysis II}

Analytical procedures: Firstly, subjects' attributes were confirmed. A t-test was conducted to identify differences between Japanese and Chinese students regarding the causes of loneliness, a sense of loneliness and isolation, and coping behaviors with loneliness. Lastly, a correlation analysis was used to investigate the relationship between the causes of loneliness, a sense of loneliness and isolation, and coping behaviors with loneliness.
6) Results and discussion

\section{(1) Subjects' basic attributes}

Subjects' attributes were confirmed (Table-5). The results showed that $41.78 \%$ of the Japanese university students lived in a dormitory, $28.36 \%$ lived at home with their family, and $26.04 \%$ lived on their own. Contrarily, $91.79 \%$ of Chinese students lived in university dormitories. Moreover, 89.93\% of the Japanese university students, and $48.31 \%$ of the Chinese university students had brothers and/ or sisters.

(2) Average scores for each scale and comparison between Japanese and Chinese students

A t-test was performed to confirm if there were differences in the scores of the Japanese and 
Table-6 Average scores for each scale and comparison between Japanese and Chinese student samples

\begin{tabular}{|c|c|c|c|c|c|c|c|c|}
\hline & \multicolumn{2}{|c|}{ Total $(\mathrm{n}=1,278)$} & \multicolumn{2}{|c|}{ JPN $(\mathrm{n}=864)$} & \multicolumn{2}{|c|}{$\mathrm{CHN}(\mathrm{n}=414)$} & \multirow{2}{*}{$\mathrm{t}$} & \\
\hline & $\mathrm{M}$ & $\mathrm{SD}$ & $\mathrm{M}$ & $\mathrm{SD}$ & $\mathrm{M}$ & $\mathrm{SD}$ & & \\
\hline \multicolumn{9}{|l|}{ Causes } \\
\hline Absence of supporters and sympathizers & 2.20 & .76 & 2.10 & .79 & 2.42 & .66 & -7.71 & $* * *$ \\
\hline Introverted thoughts & 2.31 & .73 & 2.27 & .78 & 2.39 & .63 & -3.07 & $* *$ \\
\hline Changes in the environment & 2.10 & .64 & 2.00 & .65 & 2.32 & .55 & -9.35 & $* * *$ \\
\hline Loneliness & 40.67 & 8.83 & 39.46 & 8.78 & 43.20 & 8.39 & -7.22 & $* * *$ \\
\hline \multicolumn{9}{|l|}{ Coping Behaviors } \\
\hline Interpersonal contacts & 3.30 & 1.05 & 3.50 & 1.09 & 2.87 & .83 & 11.44 & $* * *$ \\
\hline Diversions and pastimes & 3.65 & .87 & 3.77 & .90 & 3.40 & .74 & 7.77 & $* * *$ \\
\hline Enduring and standing by & 3.17 & .99 & 3.19 & 1.01 & 3.13 & .95 & n.s. & \\
\hline Use of social media & 2.90 & .96 & 2.82 & 1.01 & 3.05 & .82 & -4.33 & $* * *$ \\
\hline
\end{tabular}

Note: $* * \mathrm{p}<.01, * * * \mathrm{p}<.001$, n.s. $=$ nonsignificant, JPN $=$ Japanese, $\mathrm{CHN}=$ Chinese

Table-7 Relationship between the causes of loneliness, sense of loneliness and isolation, and Coping Behaviors with loneliness in Japanese and Chinese student samples

\begin{tabular}{|c|c|c|c|c|c|c|c|c|c|c|c|c|c|c|}
\hline & & \multicolumn{3}{|c|}{ Causes } & \multirow{2}{*}{\multicolumn{2}{|c|}{$\frac{\text { Loneliness }}{4}$}} & \multicolumn{8}{|c|}{ Coping Behaviors with Loneliness } \\
\hline & & 1 & 2 & 3 & & & \multicolumn{2}{|c|}{5} & \multicolumn{2}{|c|}{6} & \multicolumn{2}{|c|}{7} & \multicolumn{2}{|c|}{8} \\
\hline \multicolumn{15}{|c|}{ Causes } \\
\hline 1 & Absence of supporters and sympathizers & - & $.57 * * *$ & $.52 * * *$ & .78 & $* * *$ & -.19 & $* * *$ & .08 & $*$ & .23 & $* * *$ & .08 & $*$ \\
\hline 2 & Introverted thoughts & $.56 * * *$ & - & $.58 * * *$ & .73 & $* * *$ & -.21 & $* * *$ & .14 & $* * *$ & .35 & $* * *$ & .06 & \\
\hline 3 & Changes in the environment & $.40 * * *$ & $.57 * * *$ & - & .57 & $* * *$ & .03 & & .13 & $* * *$ & .16 & $* * *$ & .17 & $* * *$ \\
\hline \multicolumn{15}{|c|}{ Loneliness } \\
\hline & Loneliness & $.76 * * *$ & $.74 * * *$ & $.50 * * *$ & - & & -.29 & $* * *$ & .02 & & .28 & $* * *$ & .01 & \\
\hline \multicolumn{15}{|c|}{ Coping Behaviors with Loneliness } \\
\hline 5 & Interpersonal contacts & $-.30 * * *$ & $-.32 * * *$ & $-.11 *$ & -.39 & $* * *$ & - & & .25 & $* * *$ & -.17 & $* * *$ & .31 & $* * *$ \\
\hline 6 & Diversions and pastimes & .00 & .08 & .07 & -.04 & & .22 & $* * *$ & - & & .11 & ** & .36 & $* * *$ \\
\hline 7 & Enduring and standing by & $.30 * * *$ & $.38 * * *$ & $.16 * *$ & .31 & $* * *$ & -.21 & $* * *$ & .12 & $*$ & - & & .00 & \\
\hline 8 & Use of social media & -.01 & -.03 & .07 & -.11 & * & .37 & $* * *$ & .34 & $* * *$ & .01 & & - & \\
\hline
\end{tabular}

Note: $* \mathrm{p}<.05, * * \mathrm{p}<.01, * * * \mathrm{p}<.001$, Top right: JPN, Bottom left: CHN

Chinese students for the scales that measured the causes of loneliness, a sense of loneliness and isolation, and coping behaviors with loneliness (Table-6). The results showed that Chinese students have significantly higher scores than their Japanese counterparts in terms of loneliness (UCLA Loneliness Scale) $(\mathrm{p}<0.001)$. The Loneliness Cause Scale showed that Chinese students had significantly higher scores than their Japanese counterparts in terms of "absence of supporters and sympathizers," "introverted thoughts," and "changes in the environment" $(p<0.01-p<0.001)$. The Scale for Coping behaviors with Loneliness showed that Japanese students scored significantly higher than their Chinese counterparts for "interpersonal con- tacts" and "diversions and pastimes" $(\mathrm{p}<0.001)$. However, Chinese students scored significantly higher than their Japanese counterparts for "use of social media" $(\mathrm{p}<0.001)$, and no significant differences were found for "enduring and standing by."

(3) Relationship between the causes of loneliness in Japanese and Chinese students, sense of loneliness and isolation, and coping behaviors with loneliness

A correlation analysis was performed to investigate the relationships between the causes of loneliness, a sense of loneliness and isolation, and coping behaviors with loneliness among Chinese and Japanese university students (Table-7). 
(4) Points that Japanese and Chinese university students had in common

Both Japanese and Chinese students demonstrated a medium to strong positive correlation between loneliness and hypostatic factors as the cause of loneliness, namely "absence of supporters and sympathizers," "introverted thoughts," and "changes in the environment" (Japan: $r=0.57-$ 0.78 ; China: $r=0.50-0.76, p<0.001$ ).

The results confirmed that both Japanese and Chinese demonstrated a weakly negative correlation between loneliness and one hypostatic factor for coping behaviors with loneliness, namely "interpersonal contacts" (Japan: $r=-0.29$; China: $r=-0.39$, $\mathrm{p}<0.001$ ). Furthermore, both Japanese and Chinese students demonstrated a weakly positive correlation between loneliness and one hypostatic factor for coping behaviors with loneliness, namely "enduring and standing by" (Japan: $\mathrm{r}=0.28$; China: $\mathrm{r}=0.31, \mathrm{p}<0.001$ ).

Moreover, both Japanese and Chinese students demonstrated a weakly positive correlation between the cause of loneliness and coping behaviors with loneliness, namely "absence of supporters and sympathizers" and "enduring and standing by (Japan: $\mathrm{r}=0.23$; China: $\mathrm{r}=0.30, \mathrm{p}<0.001$ ), while both Japanese and Chinese students showed a weakly negative correlation between "introverted thoughts" and "interpersonal contacts" (Japan: $r=$ -0.21 ; China: $\mathrm{r}=-0.32, \mathrm{p}<0.001$ ). However, both Japanese and Chinese students showed a weakly positive correlation between "introverted thoughts" and "enduring and standing by" (Japan: $r=0.35$; China: $\mathrm{r}=0.38, \mathrm{p}<0.001$ ).

Furthermore, it was confirmed that both Japanese and Chinese university students demonstrated a medium to strong positive correlation between the scores for loneliness and the cause of loneliness, namely "absence of supporters and sympathizers," "introverted thoughts," and "changes in the environment." The results showed a weakly negative correlation between loneliness and the score for coping behaviors with loneliness, namely "interpersonal contacts," and a weakly positive correlation between loneliness and the score for coping behaviors with loneliness, namely "enduring and standing by." The findings indicated that the relationship between the cause of loneliness, a sense of loneliness and isolation, and coping behaviors with loneliness were similar in the Japanese and Chinese university students.

\section{(5) Differences between Japanese and Chinese university students}

Regarding the attributes of the survey subjects, $89.93 \%$ of the Japanese students and $48.31 \%$ of the Chinese students had siblings. This means that the percentage of individuals without siblings was higher for the Chinese students, indicating that approximately half the Chinese students reached adolescence as an only child. The Chinese government enforced "the One-child policy" from 1978 to 2015. It is estimated that China has over 150 million children who are below 30 years of age, that are the" only child” ${ }^{34)}$ Sun ${ }^{35)}$ cites four characteristics of individuals raised in families as an only child, stating that they are self-centered, likely to perceive loneliness and a sense of isolation from others, not very good at interacting with people of the same generation, and lack the skills and ability to become independent.

Regarding their current type of residence, $41.78 \%$ of the Japanese university students lived in dormitories, $28.36 \%$ lived in their parents' home, and $26.04 \%$ lived alone. Contrarily, $91.79 \%$ of the Chinese university students lived in dormitories. However, it is important to note that almost all university students in China live in dormitories because of regulations set forth by China's Ministry of Education. This presented major challenges for the students in adapting to group living. The results of a survey on 958 Chinese university students revealed that $40 \%$ experienced problems with their roommates ${ }^{36)}$. Liang et al. ${ }^{37)}$ reported a negative correlation between loneliness and "adaptability to life in a dormitory" and "intimacy of life in a dormitory" among Chinese university students. These students' interpersonal relationship with others in the dormitory were related to loneliness.

The researchers carried out a country-specific comparison ( $t$-test) of the scores obtained from the scales that measured the causes of loneliness, sense of loneliness and isolation, and coping behaviors with loneliness, respectively, and found that Chinese students had higher scores than their Japanese counterparts for all causes of loneliness: "Absence of supporters and sympathizers," "introverted thoughts," and "changes in the environment." Regarding loneliness and isolation, Chinese 
university students scored higher than their Japanese counterparts. These results can be explained by the attributes of the survey subjects described above. Further, more than half the Chinese university students have no siblings, they are likely to perceive loneliness intensely and were highly aware of the "absence of supporters and sympathizers" and "introverted thoughts" factors. In addition, most of these students living in dormitories experienced the "changes in the environment" factor.

Regarding scores on coping behaviors with reference to loneliness, Japanese university students scored higher than their Chinese counterparts on "interpersonal contacts" and "diversions and pastimes," and lower on "use of social media." Shinohara ${ }^{38)}$ compared the amae of Japanese and Chinese university students and found that the former exercised more amae or depended more on others than did the latter. Furthermore, since Japanese students tend to be more aware of social support than are Chinese students ${ }^{39)}$, it is suggested that they tend to cope with loneliness via "interpersonal contacts," i.e., by dealing and interacting directly with people. Chinese students, on the contrary, selected the "use of social media" more often. According to a report published by the China Internet Network Information Center (CNNIC), ${ }^{40)}$ the rate of internet use in China was $57.7 \%$ in 2018 . Further, students comprised the largest proportion of users compared to other attributes (24.8\%), smartphones were the most common device used (98.3\%), and social media was the main reason for using the Internet (94.3\%). Considering these findings, it may be beneficial to set up an environment and/or system for Chinese students to ease their sense of loneliness, and to enable them to interact with other people through social media. The results of a survey on 227 Chinese university students revealed that $75 \%$ choose to interact with others through their smartphone network. With reference to interpersonal communication, the obvious trend of depending on smartphones networks is growing. ${ }^{41)}$ University students living away from home can use the smart phone network to communicate with their family and close friends, making communication more convenient. Such services also expand the scope of interpersonal communication among university students, ena- bling them to conduct interpersonal communication anonymously. ${ }^{42)}$

A weak negative correlation $(\mathrm{r}=-0.30, \mathrm{p}<0.001)$ was confirmed for the Chinese students between "absence of supporters and sympathizers," which is a hypostatic factor for causing loneliness, and "interpersonal contacts," and for coping behaviors with loneliness. However, no significant values were confirmed for the Japanese students. It appears that when Chinese university students become strongly aware of an "absence of supporters and sympathizers," their willingness to make "interpersonal contacts" is reduced. The results of a preliminary survey showed that Chinese university students considered the presence of supporters and sympathizers who understood them as important, therefore, the absence of supporters and sympathizers affected their willingness to make interpersonal contact.

Similarities and differences exist between Japanese and Chinese students in terms of the relationships between the causes of loneliness, sense of loneliness and isolation, and coping behaviors with loneliness, respectively, because of their cultural backgrounds and social environments.

\section{Conclusion}

Japanese and Chinese version of Loneliness Cause Scale and Scale for Coping behaviors with Loneliness were developed. Chinese university students felt a stronger sense of loneliness and were more aware of the causes of their loneliness than the Japanese university student samples. Japanese university students tended to choose "interpersonal contacts" and "diversions and pastimes," as coping behaviors with loneliness, while their Chinese counterparts engaged in the "use of social media."

\section{Limitations and Future Direction}

With reference to criterion-related validity, scores on two factors of the Scale for Coping Behaviors with Loneliness, namely "diversions and pastimes" and "use of social media," were not significantly correlated with those on the UCLA Loneliness Scale. Thus, the scales developed in this study could be improved further.

The present sample size was not sufficient for generalizing the findings to the Japanese and 
Chinese university student population. Thus, future studies should investigate the characteristics of these populations. In addition, the size of the Japanese and Chinese samples differed. The Japanese sample was approximately twice that of the Chinese one. This point should be considered while interpreting the present data.

It seems that, among foreign students studying in Japan, loneliness can sometimes become a cause of maladjustment. ${ }^{43)}$ Foreign students who live in an unfamiliar culture with a different language, social system, and customs are more likely to perceive loneliness ${ }^{44)}$. Further, $40 \%$ of foreign students enrolled in Japanese schools in 2017 were from China. ${ }^{45)}$ The characteristics of loneliness experienced by students from China can be used to understand students enrolled in various universities in Japan, and can assist in providing support and necessary measures. This study investigated Chinese university students who have not studied abroad; therefore, it is recommended that future studies investigate the state of loneliness perceived by Chinese students studying in Japanese schools.

\section{Acknowledgement}

Not applicable.

\section{Funding}

This study was supported by the Private University Research Branding Project of the Japanese Ministry of Education, Culture, Sports, Science and Technology; research funding from the Institute of Health and Sports Science \& Medicine, Juntendo University; and the Joint Research Program of Juntendo University, Faculty of Health and Sports Science.

\section{Author's contributions}

$\mathrm{XY}$ designed this study, collected all the data, performed the statistical analysis, and prepared the manuscript. YK supported all process of the study (study design, data collection and manuscript preparation). Other authors gave comments according to their specialty (AK health psychology; NS psychiatry). All authors read and approved the final manuscript.

\section{Conflicting interest statement}

The authors declare that there is no conflict of interest.

\section{References}

1) Kobayashi G: What is the background behind Britain's society facing "solitude". YOMIURI ONLINE; https:// www.yomiuri.co.jp/fukayomi/20180514-OYT8T50092/ (in Japanese)

2) Hirosawa T: A Psychological Study of Loneliness: Tasks and Perspectives. Bull of KUIS, 2011; 12: 153-159. (in Japanese)

3) Sullivan HS: The interpersonal theory of psychiatry. New York, USA: W. W. Norton \& Co., 1953.

4) Perlman D, Peplau LA: Toward a Social Psychology of Loneliness. In: Duck S, Gilmour R, eds. Personal Relationships 3: Personal relationships in disorder. London, England: Academic Press, 1981: 31-56.

5) Peplau LA, Perlman D: Perspective on loneliness. In: Peplau LA, Perlman D, eds. Loneliness: A Sourcebook of Current Theory, Research and Therapy. New York, USA: Wiley, 1981: 1-18.

6) Jo Cox Commission on Loneliness: Combatting loneliness one conversation at a time, 2017. https://www.age uk.org.uk/globalassets/age-uk/documents/reports-andpublications/reports-and-briefings/active-communities/ rb_dec17_jocox_commission_finalreport.pdf

7) Lynch JJ: The Broken Heart: The Medical Consequences of Loneliness. New York, USA: Basic Books, 1977.

8) Kudoh T, Nishikawa M: A study of the feeling of loneliness: I. The reliability and validity of the revised UCLA Loneliness Scale. Japanese Journal of Experimental Social Psychology, 1983; 22: 99-108. (in Japanese)

9) Weiss RS: Loneliness: The Experience of Emotional and Social Isolation. Mass, USA: MIT Press, 1973.

10) Hammond C: Who feels lonely? The results of the world's largest loneliness study. England: BBC Radio 4, 2018; https://www.bbc.co.uk/programmes/articles/2yz hfv4DvqVp5nZyxBD8G23/who-feels-lonely-the-resultsof-the-world-s-largest-loneliness-study

11) Ochiai Y: The Structure of Loneliness in Adolescents. Tokyo, Japan: Kazamashobo, 1989. (in Japanese)

12) Fukuyama E: There is a Minister for Loneliness in The UK, Japan is more serious, is there a countermeasure? NIKKEI STYLE; https://style.nikkei.com/article/DGX MZO26837910T10C18A2EAC000/ (in Japanese)

13) Innocenti Research Centre: Child Poverty in Perspective: An overview of child well-being in rich countries, 2007; 45. UNICEF; https://www.unicef.or.jp/library/pr es_bn2007/pdf/rc7_aw3.pdf

14) Hariu M, Seto M: A Study on Loneliness-Coping Strategies during Contemporary Adolescence. Bull Kanagawa University Psychological Consultation Cent, 2011; 2: 99-105. (in Japanese)

15) Luo GL, Ruan JH, Lou CL, Fang ZW, Zhu GQ: Investigation and Analysis of the Feeling of Loneliness Among College Students. Journal of ZheJIang University (Science Edition), 2016, 43: 112-115. (in Chinese)

16) Zhang ZZ: A Survey of Loneliness of College Students at Home and Abroad. Educ Teach Forum, 2019; 9: 75-77. (in Chinese)

17) Zheng XQ: The Construction of Scales for Measuring Values: A Comparative Study between Chinese and Japanese University Students. Bull the Faculty of Educ Nagoya University (Educ Psychol), 1987; 34: 69-96. (in Japanese) 
18) Wang Y, Imagawa T: Comparative study on friendships between Japanese and Chinese university students (2): Examination based on free description. Japan Society of Personality Psychology, 2007; 16: 128-129. (in Japanese)

19) Russell D, Peplau LA, Ferguson ML: Developing a measure of loneliness. J Pers Assess, 1978; 42: 290-294.

20) Luanaigh CÓ, Lawlor BA: Loneliness and the health of older people. Int J Geriatr Psychiatry, 2008; 23: 12131221.

21) Toyoshima A, Sato S: Relationship between social support and mental health mediated by loneliness among the middle-aged and elderly: An investigation using the UCLA Loneliness Scale Version 3. Japanese Journal of Gerontology, 2013; 35: 29-38. (in Japanese)

22) Wang XD, Wang XL, Ma H: Rating Scales for Mental Health. Beijing, China: Chn Ment Health J, 1999: 284287. (in Chinese)

23) Hirosawa T: A Study on causes of loneliness, emotional responses, and coping behaviors (I). Kwansei Gakuin University School of Sociology J, 1985; 51: 157-168. (in Japanese)

24) Hirosawa T: A Study on causes of loneliness, emotional responses, and coping behaviors (II) Kwansei Gakuin University School of Sociology J, 1986; 53: 127-136. (in Japanese)

25) Moroi K: Loneliness and coping strategies in university students. The Japanese Journal of Experimental Social Psychology, 1989; 29: 141-151. (in Japanese)

26) Li YM, Jiang YJ, Li XW: Study on the Loneliness Structure of College Student. Psychol Sci, 2006; 29: 465468. (in Chinese)

27) Kawakita J: Continuation - Idea Method -Development and application of KJ method-. Tokyo: Chuokoron-Shinsha, 1970. (in Japanese)

28) Russell DW: UCLA Loneliness Scale (Version 3); Reliability, Validity, and Factor structure. J Pers Assess, 1996: 66: 20-40.

29) Hirosawa T: A Study of Loneliness (III): On causes, feelings, and coping behaviors-'. Kwansei Gakuin University School of Sociology J, 2001; 2: 85-96. (in Japanese)

30) Cheng GL: Causes and Countermeasures of College Students' Loneliness. J Hubei University of Economics (Humanities and Social Sci), 2012; 9: 152-153. (in Chinese)

31) Rubenstein C, Shaver P: The Experience of Loneliness. In: Peplau LA, Perlman D, eds. Loneliness: A Sourcebook of Current Theory, Research and Therapy. New York: Wiley, 1982: 206-223.

32) Shaver P, Furman W, Buhrmester D: Transition to College: Network changes, social skills, and loneliness. In: Duck S, Perlman D, eds. Understanding Personal
Relationships: An Interdisciplinary Approach. London: Sage, 1985: 193-219.

33) Deng LF, Wang R, Zheng RC: The Relationship between Loneliness, Coping Strategies and Temperament in College Students. Stud Psychol Behav, 2007; 5: 120-126. (in Chinese)

34) Yang SZ, Wang GZ: An Indirect Estimation Method for the Quantity of Only Child. Chinese Journal of Population Science, 2007; 4: 58-64. (in Chinese)

35) Sun R: Characteristics and Educational Issues of "Only Child" in China. Ryukoku University the bull of the Graduate Sch of Lett, 2005; 27: 258-265. (in Japanese)

36) Li HX: Survey of college student dormitory Survey of college student dormitory. China: Youth.cn, 2017; https: //edu.youth.cn/jyzx/jyxw/201710/t20171027_10926100. htm (in Chinese)

37) Liang XY, Huang Y, Wei L: Research of Relation between Solitude Sense of Students and Intimacy \& Adaptability of Dorm. Theory and Practice of Education, 2006; 26: 43-45. (in Chinese)

38) Shinohara S, Harasaki S: Amae and Social Adaptation of the Young II: A Comparison of Japan and China. Fukuoka Jogakuin University Bull, 2003; 4: 29-35. (in Japanese)

39) Koyama T, Takeo K, Tanaka T, Miyaji F, Chen JX, Pang SQ: A comparative study of depression and related factors between Japanese and Chinese nursing students. Saku University J of Nursing, 2012; 4: 29-37. (in Japanese)

40) CNNIC: Statistical Report on Internet Development in China (The 42st Survey Report), 2018. http://cac.gov. cn/wxb_pdf/CNNIC42.pdf (in Chinese)

41) Zhou BL, Deng ST: The Man-machine Dialogue, or Interpersonal Relationship: The Study of Phone Network's Impact on College Students Interpersonal Relationship. Journal of Shandong Youth University of Political Science, 2016; 3: 49-53. (in Chinese)

42) Zhuang HM: Research on the Impact of Smart Phones on College Students' Interpersonal Communication in the Era of Mobile Internet. E-Business Journal, 2019; 6: 95-96. (in Chinese)

43) Inoue T, Ito T: Chapter 4: PAC Analysis Techniques in Intercultural Counseling. An Introduction to Intercultural Clinical Psychology. Tokyo: Taga Publications, 1997: 103-137. (in Japanese)

44) Naito T: PAC Analysis of Loneliness of a Korean Student. The Japanese Association of Educational Psychology, 2002; 44: 610. (in Japanese)

45) Japan Student Services Organization (JASSO): Result of an Annual survey of International Students in Japan, 2017. https://studyinjapan.go.jp/en/_mt/2020/08/date 2017z_e.pdf 